Volume 9, No.1.4, 2020

International Journal of Advanced Trends in Computer Science and Engineering

Available Online at http://www.warse.org/IJATCSE/static/pdf/file/ijatcse5491.42020.pdf

https://doi.org/10.30534/ijatcse/2020/5491.42020

\title{
Bending Mechanism for Piezoelectric Transducer
}

\author{
Anis Maisarah Mohd Asry ${ }^{1}$, Farahiyah Mustafa ${ }^{2}$, Aznizam Ahmad ${ }^{3}, \operatorname{Sim~Sy~Yi}^{4}$, Norain Sahari ${ }^{5}$ \\ ${ }^{1}$ Faculty of Engineering Technology, Universiti Tun Hussein Onn Malaysia, Hub Pendidikan Tinggi \\ Pagoh, 86400 Panchor, Johor, Malaysia, anismaiasry@ gmail.com ${ }^{2}$ Faculty of Engineering Technology, \\ Universiti Tun Hussein Onn Malaysia, Hub Pendidikan Tinggi Pagoh, 86400 Panchor, Johor, Malaysia, \\ farahiyah@uthm.edu.my ${ }^{3}$ Faculty of Engineering Technology, Universiti Tun Hussein Onn Malaysia, Hub \\ Pendidikan Tinggi Pagoh, 86400 Panchor, Johor, Malaysia, aznizam@uthm.edu.my ${ }^{4}$ Faculty of \\ Engineering Technology, Universiti Tun Hussein Onn Malaysia, Hub Pendidikan Tinggi Pagoh, 86400 \\ Panchor, Johor, Malaysia, sysim@uthm.edu.my ${ }^{5}$ Faculty of Engineering Technology, Universiti Tun \\ Hussein Onn Malaysia, Hub Pendidikan Tinggi Pagoh, 86400 Panchor, Johor, Malaysia, \\ norains@uthm.edu.my
}

\begin{abstract}
This paper tests and analyzes a piezoelectric transducer with bending mechanism based on the bending condition of piezoelectric transducer after applying a force on the bending mechanism that increase the stress on the piezoelectric surface and thus increase the electrical charges produced An impact force is being exerted onto bending mechanism to bend the piezoelectric transducer and hence generating useable electrical power. The proposed prototype bending mechanism was built by using SolidWork soft-ware and manufactured by employing 3D printer technology to conduct the evaluation. This bending mechanism is divided into two parts, presser and support housing. The presser is design with four different diameter to test the piezoelectric transducer. A round piezoelectric transducer with the size of $50 \mathrm{~mm}$ in diameter is used to demonstrate the experiment. This piezoelectric transducer is placed in support housing and the presser is used to give pressure to the piezoelectric transducer. A subject is assigned to hold the presser and press in on the surface of the piezoelectric transducer. It can be seen from the experiment that the last presser with diameter $22.35 \mathrm{~mm}$ generated the highest output voltage about $44.0 \mathrm{~V}$. The reported mechanism is a promising candidate in the application of energy harvesting by using piezoelectric transducer for powering various low power output devices.
\end{abstract}

Keywords: Bending Mechanism; Energy; Piezoelectric Transducer; Power Generation; Renewable Energy

\section{INTRODUCTION}

In 21st century, the electrical energy become the most basic need in all our daily activities. The existing non-renewable energy cannot fulfill the demand as depletion of its resources. Energy production from this energy is considered to be one of the main key factor leading to give negative impacts to the environment and society [1]. As the non-renewable reservoirs such as fossil fuel continuously declining and limited land area for energy harvesting has prompted researcher to seek an alternate approach to harness energy from renewable energy resources [2]. Unlike non-renewable energy, these energy sources are rapid replenished as these resource will never run out. Renewable energy resources such as wind, solar and geothermal are more social and environmental friendly. However, this type of renewable energy resources are irregular and intermittent as it also vulnerable to weather and climate change. An alternative way should be proposed as a solution as climate and weather change are random and unpredictable.

We, ourselves could be an alternative source of energy. Human body can be an energy source as it contain huge of energy by consuming from the body movement and essential body function such as movement of hands and legs, bending of joint and elbow, finger movement while typing, blood motion, air movement while breathing and energy of walking. Usually, this kind of energy is wasted as heat and other type of energy, but these wasted energy could be harvest and converted into useable electrical energy. In addition, walking is the daily activity in our life and the average step take by individual a day is around 3000 to 5000 step [3], [4] will become enormous resource for this renewable energy. Harvesting the wasted energy from human are more reliable as it did not relying or depending on climate change or location [5].

In this day and age, harness energy from human body has become attraction to many researches and leading to invention of many new technologies. In the previous researches, there are several method used in generating power energy by using human footsteps. One of the research done by A. Arvind et.al., generate the electrical energy by using circular piezoelectric transducer and it is placed in the pedestrian to light up the street light [6]. Another research done by Putri.et al design an ecofriendly energy that harvest from piezoelectric tile. This tile design by using 20 pieces of PZT and it connected in 
parallel connection in $30 \times 30 \mathrm{~cm}^{2}$ and inserted in pavement area. The average output power is $6.04 \mathrm{~mW}$ [7]. A. Kamboj et.al., also conducted some research in piezoelectric field. In this research, he design a footstep power generator also by using circular piezoelectric sensors. Two batteries, 6 volt for each battery used as a storage compartment before power up load such as light [8].

However, the piezoelectric transducer produced very low electrical energy during its bending process. Therefore, it need presser and support during the bending process to enhance its output. Research by P.Madhu and her co-worker design a simple bending mechanism together with footstep tile that support the piezoelectric crystal in deflection process. The base of the plywood attached with double tape as an absorber while the top of the plywood attached with plastic bushes and rubber bushes at the end as a bending mechanism [3]. Another bending mechanism design by A.M. Abdal et.al., to improve the piezoelectric output. The researcher focused on three different types of bending mechanism for piezoelectric transducer in order to study the effect of the stress parameter in the piezoelectric output. This bending mechanism design include flat, unstressed and pre-stressed mechanism. All of this bending mechanism was tested with free fall test to measure the piezoelectric output [9]. Besides that, Chen et.al., also decided to design a frame for a piezoelectric stack as it bending mechanism. This flexible frame can also acts as shock absorber to prevent damage to the stack when sudden extreme force is applied. The result show that the power output of piezoelectric stack with frame amplify higher compared to the piezoelectric stack without the frame when giving a striking impact by a hammer [10].

This paper present the generation of power by using piezoelectric transducer with bending mechanism pressure. The output voltage of the piezoelectric transducer is low so it need helps from the bending mechanism to enhance its output. There are two part of the bending mechanism, which are support housing and presser. The piezoelectric transducer is placed in the support housing and presser is used to give pressure to the piezoelectric transducer during bending process. While letting the piezoelectric transducer to receive the pressure and have some support from the bending mechanism, it will deflect and generated more electrical energy compared to usual deflect. The presser is design with various diameter according to the size of piezoelectric transducer and one of it is design follow the bullet shape concept. The most perfect upper part 3D model suit well together with bottom part 3D model will produced highest output voltage.

\section{RESEARCH METHOD}

In this research, Lead zirconate titanate (PZT) is used as a transducer to harvest the mechanical energy from human footsteps and convert it into electrical energy. The round shape piezoelectric transducers crystalline structure with the diameter of $50 \mathrm{~mm}$ are used in this research. At normal generate this piezoelectric transducer can achieve around 0 $12 \mathrm{~V}$ for common output voltage and reaches up to $30 \mathrm{~V}$ and $5 \mathrm{~mA}$ during instant impact. The electrical energy produced by this piezoelectric transducer is low and depending on the pressure give on it. This piezoelectric transducer will deflected when there are pressure or stress applies to it.

The bending mechanism is designed by using SolidWork software and Poly Maker to print this 3D model. There are two parts in this bending mechanism which are presser and support housing. The support housing is used as a support to the piezoelectric transducer by placing the piezoelectric transducer in it. While the presser is to give pressure to the piezoelectric transducer that place in the support housing. The support housing and the presser are designed based on the shape and the size piezoelectric transducer. The support housing with diameter $40 \mathrm{~mm}$ for it middle hole and $30 \mathrm{~mm}$ for its height is designed to avoid the transducer from crack as this support housing enhance the deflection of the piezoelectric transducer. However, at the same time it also restraint the piezoelectric transducer to bend more after certain amount of the pressure applied on it.

The presser is designed with four different diameter and the last presser with different shape from the first three presser. The diameter of the first presser is $50 \mathrm{~mm}$ then decrease to 40 $\mathrm{mm}$ and $30 \mathrm{~mm}$ for second and third presser respectively. The diameter of the presser is varied from $50 \mathrm{~mm}$ to $30 \mathrm{~mm}$ as it follow the diameter of the piezoelectric transducer and decrease to $40 \mathrm{~mm}$ and $30 \mathrm{~mm}$ to reduce the contact of the presser to the surface of piezoelectric transducer. The last presser is design in bullet shape with diameter $20 \mathrm{~mm}$. This last presser is design in bullet shape as it follow the high heels concept in order to give pressure to the piezoelectric transducer.

The test is conducted by using all the presser with the support housing. This test is conducted to see which presser ensemble well with the support housing that produced the highest output voltage. The subject with body weight of 60 $\mathrm{kg}$ is assigned to hold the presser then applied pressure to the piezoelectric transducer with this model. Table 1 shows all the presser with its diameter. Figure 1 shows the support housing with its dimension. Figure 2 shows the set up for testing the piezoelectric transducer with bending mechanism. 
Table 1: The presser with different size for its diameter and heights

\begin{tabular}{|c|c|c|}
\hline Design & $\begin{array}{c}\text { Diameter of presser } \\
(\mathrm{mm})(\mathrm{d})\end{array}$ & $\begin{array}{c}\text { Height of presser } \\
(\mathrm{mm})(\mathrm{h})\end{array}$ \\
\hline & 50 & 20 \\
\hline & 40 & 20 \\
\hline & 30 & 20 \\
\hline & & 30 \\
\hline
\end{tabular}

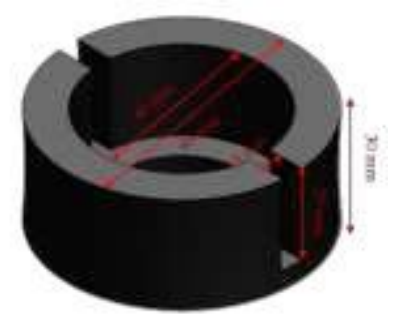

Figure 1: The support housing with its dimension

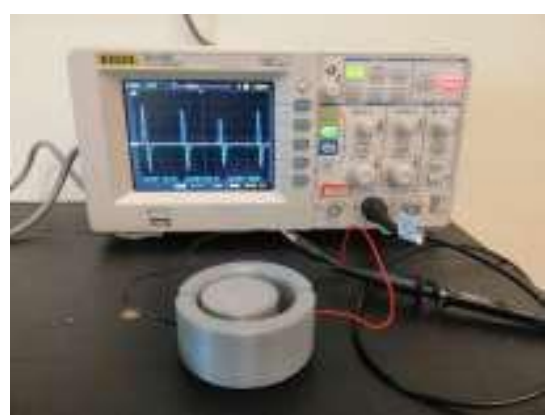

Figure 2: The set up for testing the presser together with support housing.

\section{RESULT AND ANALYSIS}

The testing has been conducted for each presser together with support housing. The piezoelectric transducer is placed in the support housing and presser is used to give pressure to piezoelectric transducer. The wire is connected to the both piezoelectric transducer and oscilloscope. The output voltage of the piezoelectric transducer is measured and recorded by using oscilloscope. The output of piezoelectric transducer is in AC waveform. Each output of the piezoelectric transducer that being press by each of the presser is different. The output of this transducer also depend on the size and shape of the presser that been used. This happen accordingly to the relationship between force, area and pressure. As the area become smaller, the pressure produce is high although the same amount the force applied. Table 2 show the output voltage and waveform for each presser.

Table 2: The output voltage together with waveform of each

\begin{tabular}{|l|c|c|c|}
\hline 3D Model & $\begin{array}{c}\text { Diameter } \\
\text { of the 3D } \\
\text { model } \\
(\mathrm{mm})\end{array}$ & $\begin{array}{c}\text { Output } \\
\text { voltage } \\
(\mathrm{V})\end{array}$ & $\begin{array}{c}\text { The voltage output } \\
\text { waveform }\end{array}$ \\
\hline $\mathrm{d}$ & 50 & 11.2 & \\
\hline & & & \\
\hline & & & \\
\hline
\end{tabular}

The first presser produces the output voltage around $11.2 \mathrm{~V}$. This output voltage is low as the diameter (d) of the presser is large about $50 \mathrm{~mm}$ with $20 \mathrm{~mm}$ height (h). This diameter size of the first presser is design based on the diameter size of the piezoelectric transducer. It follow the size of the piezoelectric transducer to make the presser fully contact with the piezoelectric transducer in order to test the output voltage based on the pressure exerted. The pressure produced is small resulted the small output voltage.

The second presser with $40 \mathrm{~mm}$ in diameter and also $20 \mathrm{~mm}$ height produced about $20.4 \mathrm{~V}$. This output voltage is higher compared to the output voltage of the first presser. Meanwhile, the output voltage generated by the piezoelectric transducer is $33.6 \mathrm{~V}$ when the third presser with diameter of $30 \mathrm{~mm}$ with 20 $\mathrm{mm}$ height is used. The output voltage of the third presser is higher compare to the second and first presser. This shows that the output voltage is high when small diameter of presser is 
used. The smaller diameter of presser produce high pressure and results to higher output voltage. This explains why the output voltage of the third presser is higher compare to the second and first presser as its diameter smaller than the other two presser.

The last presser is slightly different in shape from the other first three presser. This presser with $20 \mathrm{~mm}$ in diameter and 30 $\mathrm{mm}$ in height is in bullet shape. This presser is design in bullet shape to reduce its contact with the surface of piezoelectric transducer. The output voltage of this presser is $44.0 \mathrm{~V}$. It is the highest output voltage among the other presser. According to Pascal's law, when the surface area is small, the pressure produce is high. The output voltage of the piezoelectric transducer increase linearly with the pressure produced. Therefore, the most suitable shape and size for the presser is the last presser as it produced the highest output voltage.

\section{CONCLUSION}

This research paper outlined a bending mechanism. This mechanism improve the mechanical impact force into the deflection process of the piezoelectric transducer and thus generates higher electrical energy compared to piezoelectric transducer without the bending mechanism. Proof of concept for this bending mechanism had been performed with the testing of it by giving pressure to the presser. The proposed mechanism with diameter $20 \mathrm{~mm}$ and $30 \mathrm{~mm}$ height in bullet shape was capable of harvesting about $44.0 \mathrm{~V}$. This shows that this presser suit well with the suggested support housing. Both presser and support housing can be used to form a better piezoelectric tile to generate more power output from human footstep. In future, the piezoelectric tile can be placed in crowded area and it is specifically suitable to be placed at pavement street, stairs, ticket counter and exercise equipment such as treadmill. The walking energy that harvest by this piezoelectric tile will become useful energy and can be used to power up the light along the stairs, garden lamp, light street and other low power appliances.

\section{ACKNOWLEDGEMENT}

The authors gratefully acknowledge the support of the Malaysian Ministry of Higher Education (MOHE) through FRGS Research Grant No. 1615 and the Universiti Tun Hussein Onn Malaysia through Short - Term Grant No. U541.

\section{REFERENCES}

1. P. Nijhawan, and A. S. Oberoi. An Innovative Design of a Solar-Wind Hybrid System. Int. J. of Adv Trends in Comput Sci and Eng. Vol. 8, pp 203-207, April 2019. https://doi.org/10.30534/ijatcse/2019/15822019

2. A. Singhal, and P. Nijhawan. A Review on Solar Wind for Possible Application in Electric Vechicle. Int. J. of Adv Trends in Comput Sci and Eng. Vol. 8, pp 620-629, June 2018.

https://doi.org/10.30534/ijatcse/2019/46832019
3. P. Madhu, S. Pradeep, D. Mallappa, H. Manjunath, N. Ningappa, and M. Prashant. Electrical Power

Generation by Footsteps using Piezoelectric Transducers. Int. J. of Recent Trends in Eng \& Res, Vol. 2, pp. 108 - 115, June 2016.

4. G. Chandrika, D. Ayushi, K.Shelja, K.S. Ashish, and E.A. Nitin. Power Harvesting Through Human Locomotion. Int. J. of Adv. Res. in Elect., Electron and Instrum Eng. Vol. 6, pp. 2277-2282, April 2017.

5. D. Marshiana, S. M. Elizabeth, N. Sunitha, and C. Vinothkumar. Footstep Power production using Piezoelectric Sensors. Res. J. of Pharmacy and Technol. Vol. 9, pp. 831-834, July 2016. https://doi.org/10.5958/0974-360X.2016.00157.8

6. A. Asha, J. Jilu, S. Sreekalpa, S. Sujith, and R. Resmi. Power Generation through Human Locomotion. J. of Electron and Commun Syst. Vol. 1, pp. 1-9. 2016

7. B.A. Putri, D. Denny, and S. Sarwok Green energy harvesting from human footsteps. MATEC Web of Conf., pp. 1-3.

8. K. Akshat, H. Altamash, K. Ayush, V.K Sharma, and K. Arun Design of footstep power generator using piezoelectric sensors. 2017 ICIIECS Conf., pp. 978-980.

9. M. Ali, K. Abdal, and K. S. Leong. Impact-Driven Energy Harvesting: Effect of Stress on Piezoelectric Bender. J. of Telecommun, Electron and Comput Eng, Vol.10, pp.87-92. August 2018.

10. G. Plinio, C. Wusi, Y. Wang, and Z. Lei Design and Testing of Amplification Frame for Piezoelectric Energy Harvester. Young Investigator Review, 2018, pp. 1-19. 